\title{
Introduction: Adversariality in Argument
}

\author{
Katharina Stevens ${ }^{1} \cdot$ John Casey ${ }^{2}$
}

Published online: 8 October 2021

(c) The Author(s), under exclusive licence to Springer Nature B.V. 2021

The title of this special issue, "Adversariality in Argument", invokes thoughts of contest, of arguments with winners and losers, strategies, aggression, and hurt feelings. For argumentation theorists, adversariality is a problem because its descriptive and normative status is unclear. Is adversariality necessary? Is it good?

For much of its history, the problem of adversariality has been considered an epistemological problem. When arguers trade reasons with an eye toward victory rather than truth or understanding, to vary Epicurus' Vatican saying \#74, the real loser is very often everyone, including the apparent winner. This is because, when argument is adversarial, only the aggressive ones participate. Important reasons are ignored or not even mentioned, whit triumphs over truth, and the epistemic results are predictably spotty.

More recently, argumentation theorists have recognized that adversariality is also a central problem for the ethics of argumentation. On the one hand, resolving issues by exchanging reasons is praiseworthy precisely because it expresses respect for the rationality of one's interlocutor. And objections are needed to test arguments. It would follow then that some adversariality in the shape of for-and-against arguing is valuable. But on the other hand, arguing is not simply the exchange of reasons; arguers are real people and so they vary in their rhetorical skill, social power, or sheer confidence. It is impossible to ignore the effect these differences have on the moral aspects of exchanging reasons; an argument between unequal arguers might be an occasion for degradation or humiliation, even if the reasons are good ones, or the arguers agree. Besides, arguments come with

Katharina Stevens

katharina.stevens@uleth.ca

John Casey

j-casey1@neiu.edu

1 Department of Philosophy, University of Lethbridge, Lethbridge, Canada

2 Department of Philosophy, Northeastern Illinois University, Chicago, USA significant psychological and social costs. There are then a variety of morally significant options for behavior in argument, many of which come down to a choice whether to engage in different kinds of adversarial behavior-and none of which are easy or straight-forward.

Given this new dimension of the problem, it is no wonder that recent years have seen an explosion of interest in the problem of adversarial arguing. The debate is complicatedand those who reject all adversariality in argument may wonder whether it should be a debate at all. It would therefore be foolish to make an attempt at summarizing it. Fools that we are, that is what we would like to do here.

\section{A Short History of the Current Adversariality Debate}

As we see it, there are three main phases of the adversariality debate. The opening phase challenges the paradigmatic assumption that argumentation is and should be adversarial at its core. Reaching from the $70 \mathrm{~s}$ to the later $90 \mathrm{~s}$, this phase also saw the development of cooperative models of argumentation. The debate begins with the rejection of the notion that the sole goal of argumentation is to change the minds of others (Brockriede 1972; Gearheart 1979). However, it truly gained momentum when Moulton published "A Paradigm of Philosophy: The Adversarial Method" (1983). In this milestone paper, Moulton trained her critical sights on philosophy itself, a discipline she considered to be under the sway of the adversary paradigm. The defining feature of this paradigm is the idea that the best way to test the validity of philosophical positions is to subject them to trial by counterexample, where a proponent defends a theory and an opponent invents counterexamples meant to debunk it. Moulton concludes that the adversary paradigm results in an epistemically impoverished philosophical practice, motivated as it was by the convenience of easy measurement (counterexamples are easy to produce) rather than by sustainable theory development. She also points out that the adversary paradigm is deeply associated with masculine 
styles of reasoning and therefore excludes feminine arguers. Running on a parallel track, Lakoff and Johnson (1980) argued that the concept of argument is more broadly under the spell of metaphors of combat, where arguers attack and defend positions. Crucially, for Lakoff and Johnson as well as Moulton, such an approach is optional, however formative it be.

Against this paradigm, more cooperative forms of engaging argumentatively were proposed, for example by Cohen (1995), Foss and Griffin (1995), and Gilbert (1997). As a result, this phase of the debate did not only criticize the dominant adversarial model (later named DAM by Cohen 2015), but also resulted in the creation of a cooperative model capable of offering an alternative to it.

It would not be long before the new cooperative paradigm fell under scrutiny, and so a new phase began with the publication of Govier's (1999) book The Philosophy of Argument, which featured two chapters on the problem of adversariality. Here Govier lays out her now influential distinction between two sorts of adversariality in argument. One of them, ancillary adversariality, includes those hostile argumentative behaviors that so often silence already marginalized voices and that motivated the objections to adversariality in argument in the first place. This kind of adversariality is unnecessary to argument and should be eliminated as far as possible. However, Govier also identifies another kind of adversariality, which she calls "minimal adversariality," that she believes not only to be necessary to argument but also the main reason why argumentation is valuable. Arguing, Govier claims, requires as a practical and logical matter that an arguer is committed to a claim and recognizes that an audience is or could be opposed to it. And so arguing by its very nature requires that its participants are adversaries, at least as regards the claims under consideration.

In its turn, Govier's attempt to salvage a concept of minimum adversariality generated a flurry of responses. They concentrated, to a large part, on two related questions: Whether and how cooperative argumentation can be developed further (Bailin and Battersby 2010, 2016; Cohen 2015; Cohen and Miller 2016), and whether and what kinds of adversariality are conceptually, pragmatically, or normatively necessary for argumentation. The latter question was tackled in typical adversarial form. On the one hand, it featured those who defended the idea of an essential, minimally adversarial core in argumentation and, at the same time, offered new ways to conceptualize this core (Aikin 2011, 2017; Casey 2020). On the other hand, there were those who claimed that adversariality is eliminable from argument (though many of them agreed that adversariality was appropriate in some contexts) (Bailin and Battersby 2017; Hundleby 2010, 2013; Rooney 2010, 2012). The debate also motivated attempts at formulating normative theories that made the appropriateness of arguing adversarially dependent on the context of the individual argument (Stevens 2016, 2019; Stevens and Cohen 2018). Finally, the feminist attempts at formulating ideal, cooperative theories of argumentation prompted work that revealed the often racially and culturally insensitive ways in which predominantly white, western argumentation theorists create normative theory (Henning 2018, 2021).

The re-emergence of the adversariality debate in argumentation theory coincided with the publication of Mercier and Sperber's (2011) argumentative account of the evolutionary adaptability of reason and the associated monograph (Mercier and Sperber 2017). Their theory was accompanied by a flurry of papers across many disciplines. Its authors argue that reasoning is adaptive as a means for the persuasion of others. This explains the my-side bias as a useful tool rather than a puzzling flaw of the human mind. It also implies that human beings reason towards the truth most successfully in proponent-opponent adversarial structures. This theory of reasoning as a tool for adversarial argumentation was welcomed by some argumentation theorists (Zarefsky 2012) and has proved very influential in the debate. As such, we think of it as a third phase of the adversariality debate.

\section{The Special Issue on Adversariality in Argument}

When we decided to edit this special issue on adversariality in argument, we hoped that it would feature interesting and useful continuations of discussions that have been developing for a while and that it would reveal new directions and new questions. We have not been disappointed. Many of the entries we offer continue important lines of thought. The question of whether and in what sense adversariality is an essential feature of argumentation (call it the ontological problem) remains at the center of several papers. The papers in this group show that there are new avenues to explore, including the conditions under which adversarial argumentation arises, the goals it serves, and the impact it has on the arguers. They show that the inquiry has moved beyond the question as to whether adversariality as a whole is good or bad, necessary or unnecessary.

Scott Aikin advances a new line of reasoning for the intrinsic adversarialism of argument based on the nature of reasons qua reasons. Drawing from contrastivism, Aikin argues that since reasons have their character as reasons against contrasting classes, argument is structurally adversarial. Crucially, this is an adversariality that obtains between views rather than people.

David Godden argues against the idea that all argumentative encounters can be transformed into cooperative co-inquiry. He points out that where argumentation arises 
because of a disagreement, its adversariality is hereditary and necessitated by the epistemic commitments of the arguers. While some arguments are cooperative, attempting to make all of them cooperative would be a mistake.

Catherine Hundleby and Moira Howes engage with recent arguments that identify one kind of argumentative adversariality in the way reason giving impacts the audience's mind independent of their will. They recommend a shift in attention to the vulnerabilities of those engaged in argumentation and the associated moral questions.

Catarina Dutilh Novaes challenges the idea that argumentative adversariality is internal to argument, claiming instead that it is relevant to three other, broader purposes or teloi of argumentation: viz., consensus-building, conflict resolving and knowledge production.

Meanwhile, a second group of papers picks up on a theme that had, so far, been only a sub-plot of the debate-present (Hundleby 2013), but almost unnoticed. These texts question the assumption that it is possible to find a contextindependent "ideal" of argumentation that can answer the question whether and how much adversariality is adequate for any situation. Each in their own way, they point out the dangers of such ideals:

Marc-Kevin Daoust shows that in argumentation, as elsewhere, we need to be careful when we use ideals, like that of non-adversariality, to guide us in non-ideal circumstances. Trying to approximate such ideals, developed under the assumption of ideal circumstances, might be harmful in some real-world contexts.

Kat Stevens and Daniel Cohen argue that the debate has taken too little care to distinguish between different kinds of adversariality in argument. Normative judgments about the necessity and the desirability of adversariality must be sensitive to the kind under discussion. Attempts at giving universal all-or-nothing answers will result in epistemic and moral losses, so a context-dependent approach is necessary.

Tempest Henning uses concepts developed in the discussion surrounding epistemic injustice to tackle problems that arise from the racial and cultural insensitivities of the adversariality debate. She argues that ideals of cooperative argumentation developed by feminist argumentation-theorists forbid open aggression from Black arguers while enabling passive aggressive "white talk" that is common among white arguers.

Finally, each of the papers in our last group demonstrates that the discussion about adversariality is now mature enough to explore new directions, connect it to its historical roots and use it for application in the classroom:

Jeffrey Davis and David Godden shift the focus of the discussion of adversariality from the activity of speaking to that of listening. They show how listeners can engage in vicious adversarial behavior and make a case for the importance of virtuous listening in argumentation.
A notable hole in the literature on adversarial argument is history. Colin Guthrie King takes some first steps in the direction of remedying this by mining Aristotle's $O n$ Sophistical Refutations for insights about acceptable and non-acceptable kinds of argumentative adversariality.

Sharon Bailin and Mark Battersby apply insights from the adversariality debate to the context of critical thinking education. They provide suggestions for ways in which useful forms of argumentative adversariality can be integrated into teaching a collaborative framework for argumentation.

We think that the contributions to this special issue fulfill the function we originally intended. But they do more. They show that what began as a handful of papers questioning the adversarial paradigm and seeking alternatives is now a complex and multifaceted field of inquiry at the heart of the ethics of arguing. Because of this, and because of the exciting quality of each of the papers we selected, we are excited to offer you this special issue.

\section{References}

Aikin SF (2011) A defense of war and sport metaphors in argument. Philos Rhetor 44(3):250-272. https://doi.org/10.5325/philrhet. 44.3.0250

Aikin SF (2017) Fallacy theory, the negativity problem, and minimal dialectical adversariality. Cogency 9(1):7-19

Bailin S, Battersby M (2010) Reason in the balance: an inquiry approach to critical thinking, 1st edn. McGraw-Hill Ryerson, Toronto

Bailin S, Battersby M (2016) Fostering the virtues of inquiry. Topoi 35(2):367-374. https://doi.org/10.1007/s11245-015-9307-6

Bailin S, Battersby M (2017) DAMned if you do, DAMned if you don't: Cohen's "Missed opportunities". OSSA Conference Archive. https://scholar.uwind sor.ca/ossaarchive/OSSA11/papersandc ommentaries/90

Brockriede W (1972) Arguers as lovers. Philos Rhetor 5(1):1-11

Casey J (2020) Adversariality and argumentation. Informal Logic 40(1):77-108. https://doi.org/10.22329/il.v40i1.5969

Cohen D (1995) Argument is war...and war is hell: philosophy, education, and metaphors for argumentation. Informal Logic 17(2):177-188

Cohen D (2015) Missed opportunities in argument evaluation. In: van Eemeren FH, Garssen B (eds) Reflections on theoretical issues in argumentation theory. Springer, Dordrecht

Cohen DH, Miller G (2016) What virtue argumentation theory misses: the case of compathetic argumentation. Topoi 35(2):451-460. https://doi.org/10.1007/s11245-015-9334-3

Foss SK, Griffin CL (1995) Beyond persuasion-a proposal for an invitational rhetoric. Commun Monogr 62(1):2-18. https://doi. org/10.1080/03637759509376345

Gearheart S (1979) The womanization of rhetoric. Women's Stud Int Q 2:195-201

Gilbert MA (1997) Coalescent argumentation. Lawrence Erlbaum Associates, Mahwah

Govier T (1999) The philosophy of argument. Vale Press, Virginia

Henning T (2018) Bringing wreck. Symposion 5(2):197-211

Henning T (2021) "I Said What I Said"-black women and argumentative politeness norms. Informal Logic 41(1):17-39. https://doi. org/10.22329/il.v41i1.6687 
Hundleby C (2010) The authority of the fallacies approach to argument evaluation. Informal Logic. https://doi.org/10.22329/il.v30i3.3035

Hundleby C (2013) Aggression, politeness, and abstract adversaries. Informal Logic 33(2):238-262. https://doi.org/10.22329/il.v33i2. 3895

Lakoff G, Johnson M (1980) Metaphors we live by. University of Chicago Press, Chicago

Mercier H, Sperber D (2011) Why do humans reason? Arguments for an argumentative theory. Behav Brain Sci 34(2):57-74. https:// doi.org/10.1017/S0140525X10000968

Mercier H, Sperber D (2017) The enigma of reason. Harvard University Press, Cambridge

Moulton J (1983) A paradigm of philosophy: the adversarial method. In: Harding S, Hintikka M (eds) Discovering reality: feminist perspectives on epistemology, metaphysics, methodology, and philosophy of science. Springer, Dordrecht

Rooney P (2010) Philosophy, adversarial argumentation, and embattled reason. Informal Logic 30(3):203-234. https://doi.org/10.22329/ il.v30i3.3032
Rooney P (2012) When philosophical argumentation impedes social and political progress: when philosophical argumentation impedes progress. J Soc Philos 43(3):317-333. https://doi.org/10.1111/j. 1467-9833.2012.01568.x

Stevens K (2016) The virtuous arguer: one person four roles. Topoi 35(2):375-383. https://doi.org/10.1007/s11245-015-9309-4

Stevens K (2019) The roles we make others take: thoughts on the ethics of arguing. Topoi. https://doi.org/10.1007/s11245-019-09659-0

Stevens K, Cohen D (2018) The attraction of the ideal has no traction on the real: on adversariality and roles in argument. Argum Advocacy. https://doi.org/10.1080/10511431.2018.1504584

Zarefsky D (2012) A challenge and an opportunity for argumentation studies. Argum Advocacy 48(3):175-178. https://doi.org/10.1080/ 00028533.2012 .11821763

Publisher's Note Springer Nature remains neutral with regard to jurisdictional claims in published maps and institutional affiliations. 